\title{
Educação e sustentabilidade: o porvir dos povos indígenas no ensino superior em Mato Grosso do Sul
}

\author{
Education and sustainability: the future of the indigenous peoples in higher learning \\ in Mato Grosso do Sul \\ L'éducation et la soutenabilité: l'avenir des peuples indigènes dans l'enseignement \\ supérieur à Mato Grosso do Sul \\ Educación y sostenibilidad: el porvenir de los pueblos indígenas en la enseñanza superior en \\ Mato Grosso do Sul
}

\author{
Marta Regina Brostolin* \\ Simone Figueiredo Cruz**
}

Recebido em 14/12/2009; revisado e aprovado em 20/1/2010; aceito em 10/2/2010

\begin{abstract}
Resumo: Nos últimos anos, o governo brasileiro tem adotado medidas de ações afirmativas na área educacional visando promover a equidade e a inclusão social das populações desfavorecidas e, entre elas, os povos indígenas. Passados os anos e, com os avanços na implementação dos direitos constitucionais dos povos indígenas, aumenta a procura destes por educação, inclusive o ensino superior que, até três a quatro anos atrás, apresentava uma demanda muito tímida. Neste cenário, duas Universidades vêm se destacando, a Universidade Católica Dom Bosco (UCDB), pela sua trajetória histórica no trabalho dos salesianos com os povos indígenas e a Universidade Estadual de Mato Grosso do Sul (UEMS) que, a partir de 2003, instituiu uma política de cotas e de bolsas para esse importante segmento no Estado de Mato Grosso do Sul. Este trabalho se insere neste contexto, apresentando dados relativos à situação dos acadêmicos indígenas em MS e se propõe também a contribuir para o debate sobre o porvir das populações indígenas no ensino superior, entendendo ser a educação reconhecida por eles como um dos elementos chaves para a viabilização de seus projetos de autonomia e sustentabilidade e o grande desafio posto as instituições de ensino superior no que tange à construção de relações mais simétricas e à promoção do diálogo intercultural em seus espaços acadêmicos.
\end{abstract}

Palavras-chave : Povos indígenas. Educação superior. Sustentabilidade e interculturalidade.

Abstract: In recent years, the Brazilian government has adopted affirmative measures in the area of education seeking to promote equality and social inclusion of needy populations and, among them, the indigenous peoples. With the passing of the years and with advances in the implementation of the constitutional rights of the indigenous peoples, they have more and more sought for education, including higher learning which three or four years ago represented a very small demand. In this scenario, two universities stand out, the Universidade Católica Dom Bosco (UCDB), with the historical trajectory of the work of the salesians with indigenous peoples and the Universidade Estadual de Mato Grosso do Sul (UEMS), which as of 2003, instituted a policy of quotas and scholarships for this important segment in the State of South Mato Grosso. This study is inserted in this context presenting data relative to the situation of indigenous students in South Mato Grosso who are ready also to contribute to the debate on the future of the indigenous populations in higher learning with the understanding that it is the education recognized by them as one of the key elements for making viable their projects of autonomy and sustainability and the great challenge before the institutions of higher learning as to the construction of more symmetrical relationships and the promotion of an intercultural dialogue within their walls.

Key-words: Indigenous peoples. Higher learning. Sustainability and interculturality.

Résumé: Ces dernières années, le gouvernement brésilien a adopté des mesures d'actions affirmatives en matière d'éducation pour promouvoir l'équité et l'inclusion sociale des populations défavorisées, et parmi elles, les peuples indigènes. Au fil des années avec les progrès réalisés dans la mise en œuvre des droits constitutionnels des peuples indigènes, la demande d'éducation augmente, y compris l'enseignement supérieur, une demande qu'il y a trois ou quatre ans était très timide. Dans ce contexte, deux universités ont été ressorties, l' Universidade Católica Dom Bosco (UCDB), par sa trajectoire historique dans le travail des prêtres salésiens avec les peuples indigènes et l' Universidade Estadual de Mato Grosso do Sul (UEMS), qui, depuis 2003, a instauré une politique de quotas et de bourses d'études pour ce secteur important dans l'État de Mato Grosso do Sul. Ce travail s'inscrit dans ce contexte en présentant des données sur la situation des étudiants indigènes à Mato Grosso do Sul et propose également de contribuer au débat sur l'avenir des peuples indigènes dans l'enseignement supérieur. En outre, on comprend que l'éducation reconnue par eux est l'un des éléments clés pour la viabilité de leurs projets d'autonomie et de soutenabilité. Aujourd'hui, le plus grand défi pour les institutions d'enseignement supérieur à l'égard de la construction de relations plus symétriques est la promotion du dialogue interculturel dans leur domaine académique.

Mots-clés: Peuples indigènes. Enseignement supérieur. Soutenabilité et interculturel..

Resumen: Los últimos años, el gobierno brasileño ha adoptado medidas de acciones afirmativas en el área educativa visando promover la equidad y la inclusión social de las poblaciones desfavorecidas y, entre ellas, los pueblos indígenas. Con el paso de los años y, con los avances en la implementación de los derechos constitucionales de los

\footnotetext{
*UCDB. E-mail: brosto@ucdb.br

** Mestre em Educação pela UCBD e Coordenadora Pedagógica do SESI - Campo Grande-MS. E-mail: simonefc66@hotmail.com
} 


\begin{abstract}
pueblos indígenas, aumenta la búsqueda de estos por educación, inclusive la enseñanza superior que hasta tres a cuatro años atrás presentaba una demanda muy tímida. En este escenario, dos Universidades vienen destacándose, la Universidade Católica Dom Bosco (UCDB), por su trayectoria histórica en el trabajo de los salesianos con los pueblos indígenas y la Universidade Estadual de Mato Grosso do Sul (UEMS), que a partir de 2003, instituyó una política de cotas y de becas para este importante segmento en el Estado de Mato Grosso del Sur. Este trabajo se inserta en este contexto presentando datos relativos a la situación de los académicos indígenas en MS y se propone también a contribuir para el debate sobre el porvenir de las poblaciones indígenas en el enseñanza superior, afirmando ser la educación reconocida por ellos como uno de los elementos claves para la viabilidad de sus proyectos de autonomía y sostenibilidad y el gran desafío impuesto a las instituciones de enseñanza superior en lo que respecta a la construcción de relaciones más simétricas y la promoción del diálogo intercultural en sus espacios académicos.

Palabras clave: Pueblos indígenas. Educación superior. Sostenibilidad e interculturalidad.
\end{abstract}

\section{Considerações iniciais}

A política brasileira educacional tem se pautado no pressuposto de que a escola é o principal mecanismo para o desenvolvimento de uma sociedade democrática e igualitária. Partindo desta premissa, as ações afirmativas na área educacional e, entre elas, o Programa Diversidade na Universidade/ MEC, com vistas a promover a equidade e a inclusão social das populações mais desfavorecidas e descriminadas, incluindo neste mote os afrodescendentes e indígenas.

A expectativa em relação à escola é compartilhada também por povos indígenas que creditam à escola um papel fundamental em seu relacionamento com a sociedade envolvente como fator de emancipação social. A partir da promulgação da Constituição Federal de 1988, o Estado brasileiro reconhece aos povos indígenas o direito a uma cidadania diferenciada, por meio do reconhecimento de seus direitos territoriais e culturais e a questão da especificidade passa a ser gradativamente reconhecida e normatizada.

A "educação diferenciada" passa a ser o discurso orientador das políticas públicas, no entanto, muitos povos indígenas ainda olham com certa restrição o termo diferenciado, pois não compreendem com clareza o significado e o percebem como discriminatório, no sentido do não acesso às informações e conhecimentos necessários para viver num mundo globalizado e tecnológico. Junta-se a essa questão a baixa qualidade do ensino básico nas escolas das aldeias indígenas, bem como a necessidade de melhor formação para os professores indígenas. Essas demandas têm levado os povos indígenas a reivindicarem, através de seus movimentos e organizações, um ensino que atenda às especificidades e necessidades de suas realidades.
De acordo com Souza Lima e Hoffmann (2004, p. 171) "há dois vieses diferentes, mas historicamente entrelaçados, que têm sido percebidos de modo separado e que, todavia, confluem na busca dos povos e organizações indígenas por formação no ensino superior". Os dois vieses a que os autores se referem são: a busca por cursos de formação específica para professores indígenas e a procura por capacitação para gerenciar seus territórios e os desafios de um novo cenário de interdependência entre os povos indígenas e o Estado no Brasil.

$\mathrm{O}$ primeiro viés relaciona-se à educação escolar imposta aos indígenas pelas escolas criadas pelo Serviço de Proteção ao Índio - SPI (criado em 1910), voltada para o ensino das primeiras letras, centrado no ensino da língua portuguesa em detrimento das línguas indígenas, e tornou-se uma rede nacional de escolas indígenas sob a gestão da FUNAI (SOUZA LIMA e HOFFMANN, 2004). Somou-se a esse trabalho a ação educativa missionária através de várias ordens religiosas e, entre outras, a dos salesianos, que iniciaram seu trabalho há mais de cem anos com povos indígenas no Alto Rio Negro, no Amazonas, Mato Grosso e Mato Grosso do Sul.

As décadas de 70 e 80, século passado, foram decisivas no que tange à contestação da ação educativa praticada pela FUNAI e missões tradicionais. Instituições da sociedade civil iniciaram um processo de severas críticas ao modelo escolar imposto e à tutela do Estado, propondo então modelos alternativos pautados em práticas diferenciadas e interculturais, instituídas e asseguradas pela Constituição Brasileira de 88 e legislação educacional posterior ${ }^{1}$.

Nesse panorama, as populações indígenas reivindicam a implantação e ampliação do ensino básico em suas aldeias, bem 
como a formação de professores indígenas em programas especiais de nível médio e superior. Muitas são as experiências em andamento em vários estados brasileiros e contam com o apoio de ONGs indigenistas, organizações de professores indígenas e universidades.

O outro viés, segundo Souza Lima e Hoffmann (2004), refere-se à necessidade dos povos indígenas de terem quadros capacitados para construírem novos relacionamentos com o Estado brasileiro e com redes sociais nos contextos locais, regionais, nacionais e, até mesmo, internacionais, sem a mediação de profissionais técnicos não-indígenas. Nesta questão, buscam cursos em nível superior em diversas áreas.

Nesse processo, a cada ano e ou semestre, aumenta o número de jovens indígenas que deixam as aldeias em busca de uma formação acadêmica que lhes propicie conhecimento e experiência profissional, enfim, os capacite a enfrentarem o mundo globalizado e a desenvolverem, posteriormente, no retorno as suas aldeias após a conclusão do curso, um trabalho mais qualificado em prol da qualidade de vida e autonomia da comunidade. Se até algum tempo atrás eram poucos, hoje são aproximadamente 600 acadêmicos índios inseridos nas diversas instituições de ensino superior da capital e no interior do Estado de Mato Grosso do Sul, oriundos principalmente das etnias Terena, KaiowáGuarani e Kadiwéu.

Neste universo, este texto se propõe a contribuir para o debate sobre o porvir das populações indígenas por ensino superior entendendo ser a educação reconhecida por eles como um dos elementos chaves para a viabilização de seus projetos de autonomia e sustentabilidade.

\section{A educação escolar indígena e a demanda por ensino superior: breve panorama}

A história da educação escolar indígena no Brasil tem seu início nos primeiros tempos da colonização. Não só pela ação educativa dos jesuítas, com seus internatos e catequese, mas principalmente porque a necessidade da escolarização surge a partir da realidade de contato das sociedades indígenas com os colonizadores, ou com o que re- presenta hoje a sociedade nacional.

Revisitando brevemente a história, pode-se dizer que, no Período Imperial, não houve uma política indigenista, como também não houve sequer uma política de educação nacional. Santos (1994, p. 94) confirma que "o primeiro projeto de Constituição do Brasil, elaborado em 1823, fazia uma referência à criação de estabelecimentos para a catequese e a civilização dos índios (Título XIII, Art. 254)". Todavia, a Constituição de 1824 foi aprovada sem qualquer referência aos índios.

No início do governo republicano, a questão indígena foi tratada da forma estabelecida no período monárquico. Porém, em 20/7/1910, pelo Decreto n. 8.072, foi criado o Serviço de Proteção aos Índios e Localização de Trabalhadores Nacionais - SPILTN, o que, de certa forma, vinculou a trajetória da questão indigenista à dos trabalhadores rurais, até recentemente, sem deixar de continuarem concentrados os poderes políticos e econômicos na aristocracia rural.

Em 1985, a Nova República e o governo Sarney aumentam a expectativa de mudanças no Estado e na sociedade brasileira. Começou-se a exigir uma Assembléia Nacional Constituinte para que uma nova Constituição substituísse a que vigorou durante o regime militar. Os professores perfilaram-se com a sociedade civil, durante todo o movimento.

Significativa parcela dos povos indígenas também se mobilizou para garantir que os seus direitos fossem contemplados na nova Constituição. Como afirmou Darlene Taukane (1998, p. 31), índia Kurã-Bakairi, durante a Conferência Ameríndia de Educação: "Os povos indígenas começaram a tomar atitude diante da dominação, da manobra na década de 70 e aparece no cenário nacional com mais evidência na década de $80^{\prime \prime}$, tendo por luta política a defesa dos seus territórios e a autonomia e participação no cenário político nacional.

A consequência destas mobilizações revelou-se no Capítulo VIII, e seus Artigos 231 e 232 da Constituição Federal, aprovada em 5 de outubro de 1988, que expressam uma histórica mudança nas relações do Estado brasileiro com os povos indígenas: novos sujeitos políticos da sociedade nacional. 
Pela primeira vez na história das constituições brasileiras as preocupações com os povos e culturas indígenas saíram da condição de dispositivos isolados para vir a articularse em um capítulo específico, expressando uma concepção jurídica respeitosa, consistente e moderna. Entretanto, uma legislação específica que viria a substituí-la, o Estatuto das Sociedades Indígenas (PL 2.057/91), permanece em tramitação no Congresso Nacional desde 1991.

Neste cenário, concretizou-se então o surgimento legal de uma educação escolar indígena prevista em artigos da atual Lei de Diretrizes e Bases da Educação Nacional - a LDBEN, Lei 9394/96. Uma educação escolar indígena cuja prática passa a depender de um novo gestor: o Ministério da Educação, que até então, nenhum conhecimento detinha da realidade indígena.

Na década de 90, a educação escolar oferecida nas aldeias passou a ser objeto de investigação sistemática por parte de comunidade acadêmica; porém, restrita a etnólogos e linguístas. Mangolim (1999) ressalta que o interesse da comunidade acadêmica foi despertado por grandes movimentações indígenas, embasadas na necessidade de resolver problemas concretos de subsistência, saúde, educação, na perspectiva de um mundo globalizado.

Perante essa trajetória e inserida na problemática do contato, a educação escolar indígena no Brasil só começou a receber atenção especial, no contexto do movimento pelos direitos indígenas, há cerca de três décadas e, vive, atualmente, momentos importantes de sua construção histórica. Desde aqueles velhos tempos de colonização até hoje muita coisa mudou na educação, no Brasil e no mundo, embora a questão básica da polaridade ainda permaneça: a relação entre culturas diferentes, a relação entre o eu e o outro, entre igualdade e diferença.

Embora algumas ações tenham se iniciado no período de 1991-1994, foi entre 1995-2002 que a Coordenação Geral de Apoio às Escolas Indígenas (CGAEI) / Secretaria de Educação Fundamental/MEC efetivamente deslanchou uma atividade que resultou no atendimento de mais de $100 \mathrm{mil}$ estudantes indígenas, em uma rede de cerca de 1.392 escolas indígenas, assistidas por mais de 4 mil professores que trabalham em elevada porcentagem (mais ou menos $75 \%$ ) junto com a seus próprios povos (SOUZA LIMA e HOFFMANN, 2004).

Se essa dinâmica se deu no nível federal, responsável por normatizar, planejar e supervisionar a educação indígena, nos níveis estadual e municipal, responsáveis pela execução, foi frequente o preconceito, a ignorância, o despreparo e o descumprimento ou a aplicação das normas gerais.

Passados os anos, os avanços na implementação dos direitos constitucionais dos povos indígenas por parte dos órgãos competentes foram, de certa forma, tímidos, e devem-se mais esses avanços à luta dos próprios indígenas que adquiriram significativa visibilidade no cenário nacional e internacional no âmbito político, criando organizações indígenas e ocupando de forma crescente espaços significativos nas esferas de administração local, regional e nacional.

Mato Grosso do Sul é um estado que abriga um dos maiores contingentes indígenas do Brasil e possui uma diversidade étnica formada pelos povos Kaiowá-Guarani, Terena, Kadwéu, Ofaie, Guató, Kinikinau, Kamba e Atikun, em torno de 69 mil índios (FUNASA, 2007). Estes povos estão confinados em áreas reduzidas e com uma saturação demográfica, praticamente sem recursos naturais e sofrendo um processo ininterrupto de pauperização (BROSTOLIN, 2005).

Diante essa problemática e o avanço da educação básica nas aldeias, em torno de 300 escolas de Ensino Fundamental e 12 escolas de Ensino Médio, cresce a demanda por ensino superior que até três a quatro anos atrás era muito tímida, pois existia uma pequena parcela de indígenas com nível superior, resultado do esforço socioeconômico pessoal ou familiar. Atualmente, as lideranças e comunidades, principalmente, das etnias Terena, Kaiowá-Guarani e Kadiwéu estão buscando as instituições de educação superior como um espaço estratégico de luta por seus direitos e emancipação social. 


\section{O porvir dos povos indígenas na educação superior em Mato Grosso do Sul}

Neste cenário, duas Universidades vêm se destacando no atendimento da demanda indígena. A Universidade Católica Dom Bosco (UCDB) pela sua trajetória histórica no trabalho dos salesianos com os povos indígenas através de um programa de bolsas sociais vinculadas ao Programa Rede de Saberes e a Universidade Estadual de Mato Grosso do Sul (UEMS), que a partir de 2003, instituiu uma política de cotas e de bolsas para este importante segmento no Estado de Mato Grosso do Sul. A introdução do sistema de reserva de cotas deu-se a partir da Lei Estadual n. 2589/2002, e da Resolução COUNI/UEMS n. 241/2003 que reserva $10 \%$ das vagas de todos os cursos para alunos indígenas, totalizando 164 vagas já no seu primeiro ano de existência.

A partir de 2003, o porvir no ensino superior por parte dos povos indígenas tornou-se uma realidade crescente, porém a permanência é um grande problema, já que as dificuldades em manter-se nos cursos/IES são muitas: de ordem financeira: material didático (livros, xerox), alimentação, transporte, moradia; de ordem pessoal acadêmica: defasagem de conteúdos, de exclusão digital, de cumprimento de prazos e horários, de compreensão de textos científicos, o que exige um pensamento mais intelectualizado valorizado pela academia, diferente do estilo de aprendizagem perceptivo do sujeito indígena que aprende através de uma pedagogia indígena comunitária, na relação com a terra, seus pares e com a natureza (BROSTOLIN e CRUZ, 2009); e de ordem socioafetiva: dificuldade no relacionamento com colegas e professores devido à timidez e reserva, um traço característico da personalidade do aluno indígena e, muitas vezes, a discriminação e o preconceito explícito ou implícito em atitudes de desvalorização e zombarias.

Para enfrentar esta problemática e contexto se insere na universidade o Programa Rede de Saberes, gestado no final de 2005, com o objetivo concreto de favorecer a permanência dos acadêmicos no ensino superior.

Pelo caráter inovador do projeto, é relevante retomar seu processo de elaboração a partir da proposta do Trilhas do Conhecimento ${ }^{2}$. Este, segundo Urquiza (2007), foi lento e com muitas negociações, pois, pela primeira vez, se tentava uma parceria neste nível entre duas instituições universitárias, sendo uma pública e outra de caráter particular. Os desafios foram muitos, inicialmente de ordem institucional, no sentido de encontrar os papéis de cada equipe já na elaboração do projeto e, mais à frente, na constituição das respectivas equipes de gestão e coordenação das ações.

Em fevereiro de 2006, iniciaram-se as atividades do Programa Rede de Saberes: permanência de indígenas no Ensino Superior. O Programa tem por objetivo desenvolver ações de apoio aos alunos indígenas em sua trajetória acadêmica. Na concretização das metas propostas, o programa desenvolve as seguintes ações: capacitação de docentes, estudantes e pessoal administrativo sobre a questão indígena; participação e ou organização de eventos acadêmicos; apoio à pesquisa de alunos índios; cursos e tutorias para acadêmicos índios; implementação do Centro de Documentação Teko Arandu; preparação de alunos para ingresso em programas de pós-graduação stricto sensu e levantamento da situação dos alunos indígenas no ensino superior em MS. O Programa oferece ainda estrutura física de apoio, tais como: centro de convivência e laboratório de informática.

Entre as diversas e significativas ações desenvolvidas pelo Programa Rede de Saberes destaca-se o levantamento realizado nas IES sobre a situação dos acadêmicos indígenas em MS. Esta realidade era desconhecida pela sociedade e órgãos públicos, sendo estes dados disponibilizados para pesquisadores, comunidades indígenas e outros em um banco de dados no Centro de Documentação Teko Arandu, no NEPPI/UCDB. Do mapeamento realizado em MS, algumas informações pertinentes a esta discussão são apresentadas abaixo: 


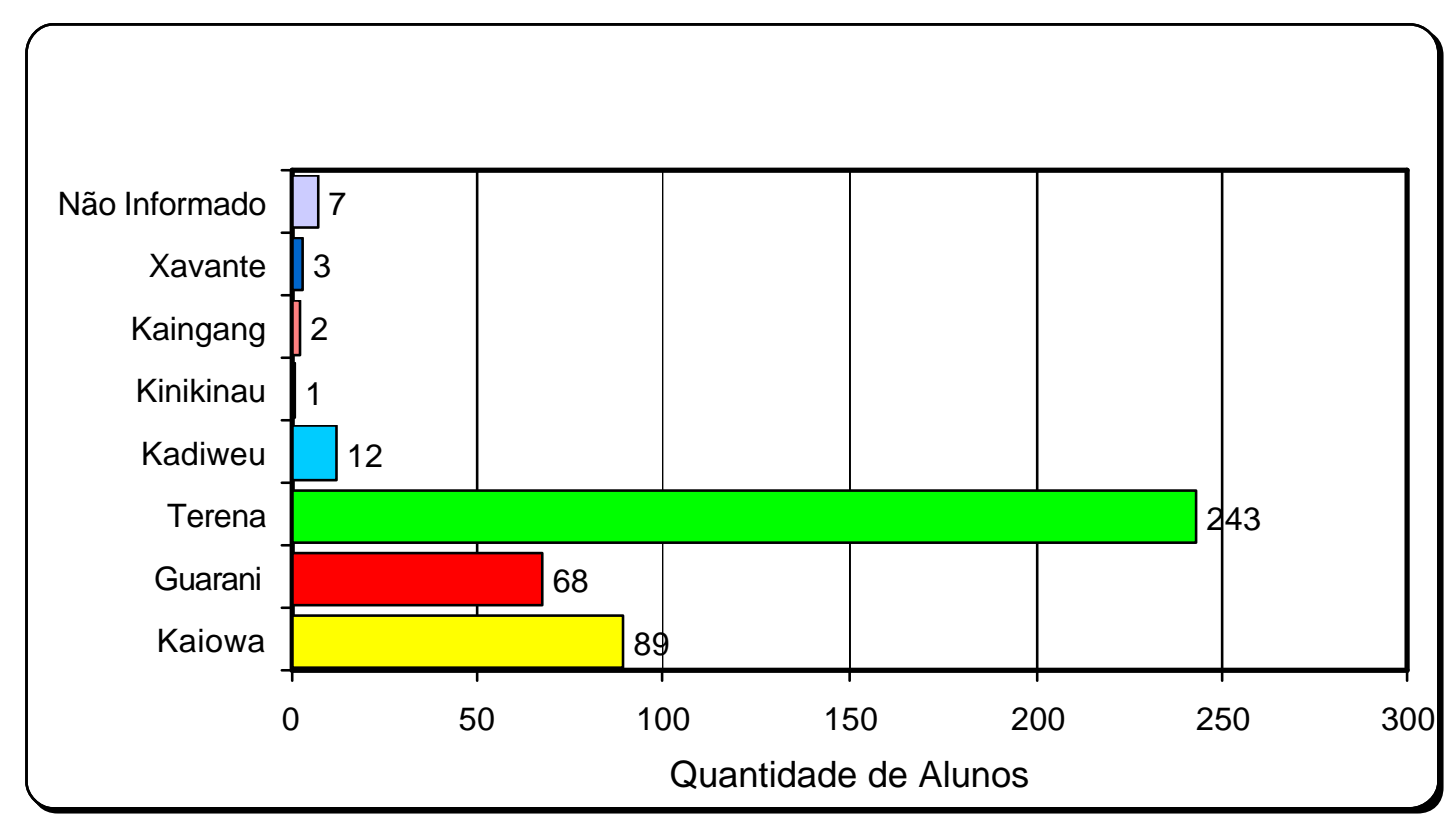

Figura 1 - Etnia dos Acadêmicos Indígenas de MS - 2009.

Estima-se que existam atualmente em torno de 600 acadêmicos indígenas estudando nas diversas instituições de ensino superior no Estado, entretanto, o levantamento realizado por pesquisadores das quatro IES envolvidas no programa conseguiu entrevistar 429 estudantes. Destes, de acordo com o gráfico acima, as etnias que se destacam são os Terena, os Kaiowa e os Guarani. Cons- tata-se a predominância de alunos Terena determinada pela proximidade de suas aldeias com as cidades e com os campi, bem como um contato interétnico desde o século XIX que favorece a relação e transição entre o mundo indígena e a sociedade globalizada respaldado por uma imagem do Terena enquanto cortês e aberto à exterioridade (PEREIRA, 2009).

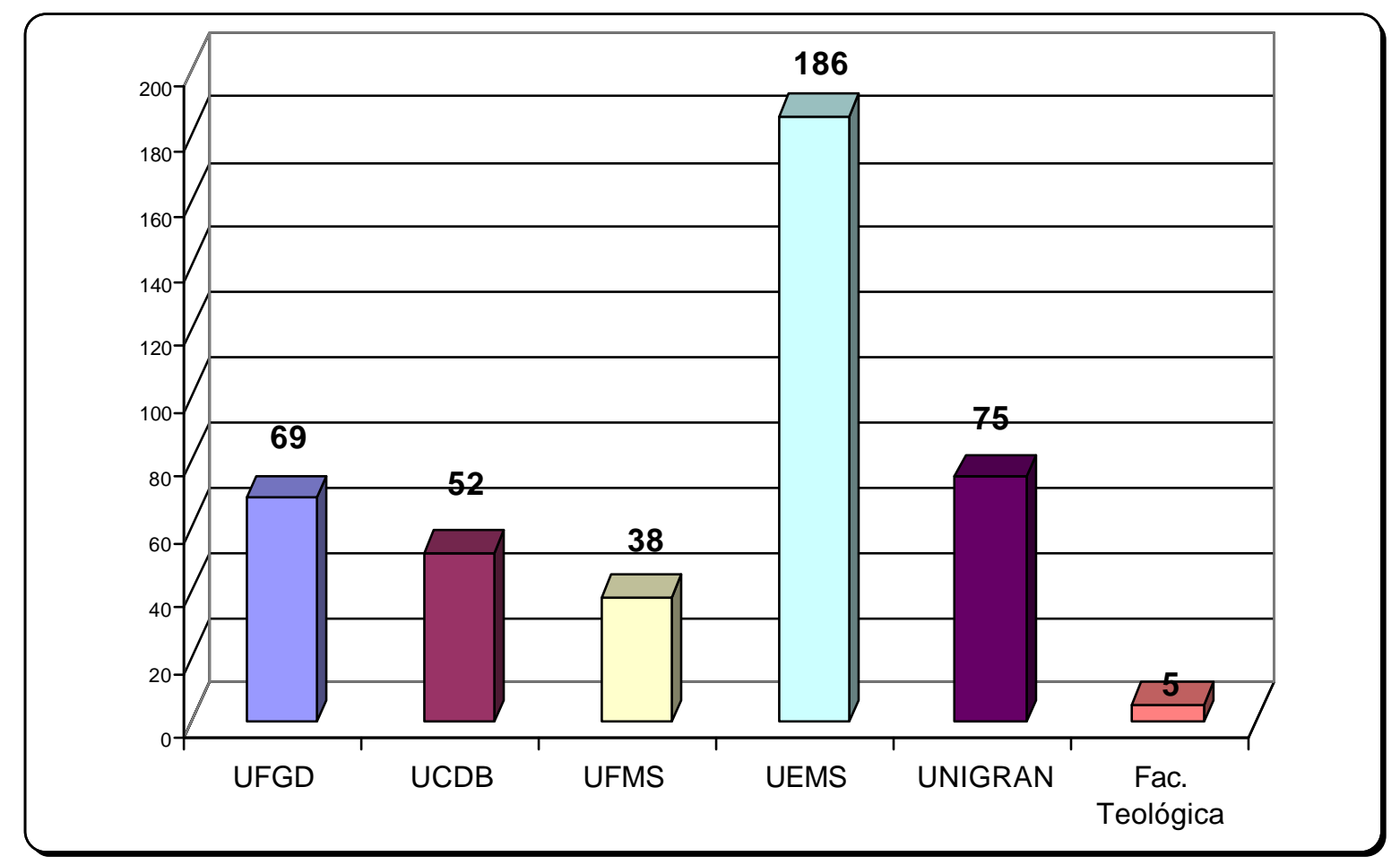

Figura 2 - Acadêmicos por Instituição - 2009. 
Constata-se que a UEMS concentra um maior número de alunos devido ao sistema de reserva de cotas e bolsas. Em segundo lugar, destaca-se a UNIGRAN, que mantém convênio com a FUNAI; depois, a UFGD, através da licenciatura específica para professores Kaiowa-Guarani e a UCDB, via PROUNI, programa federal ainda pouco utilizado, convênio FUNAI e bolsas sociais vinculadas ao Programa Rede de Saberes.

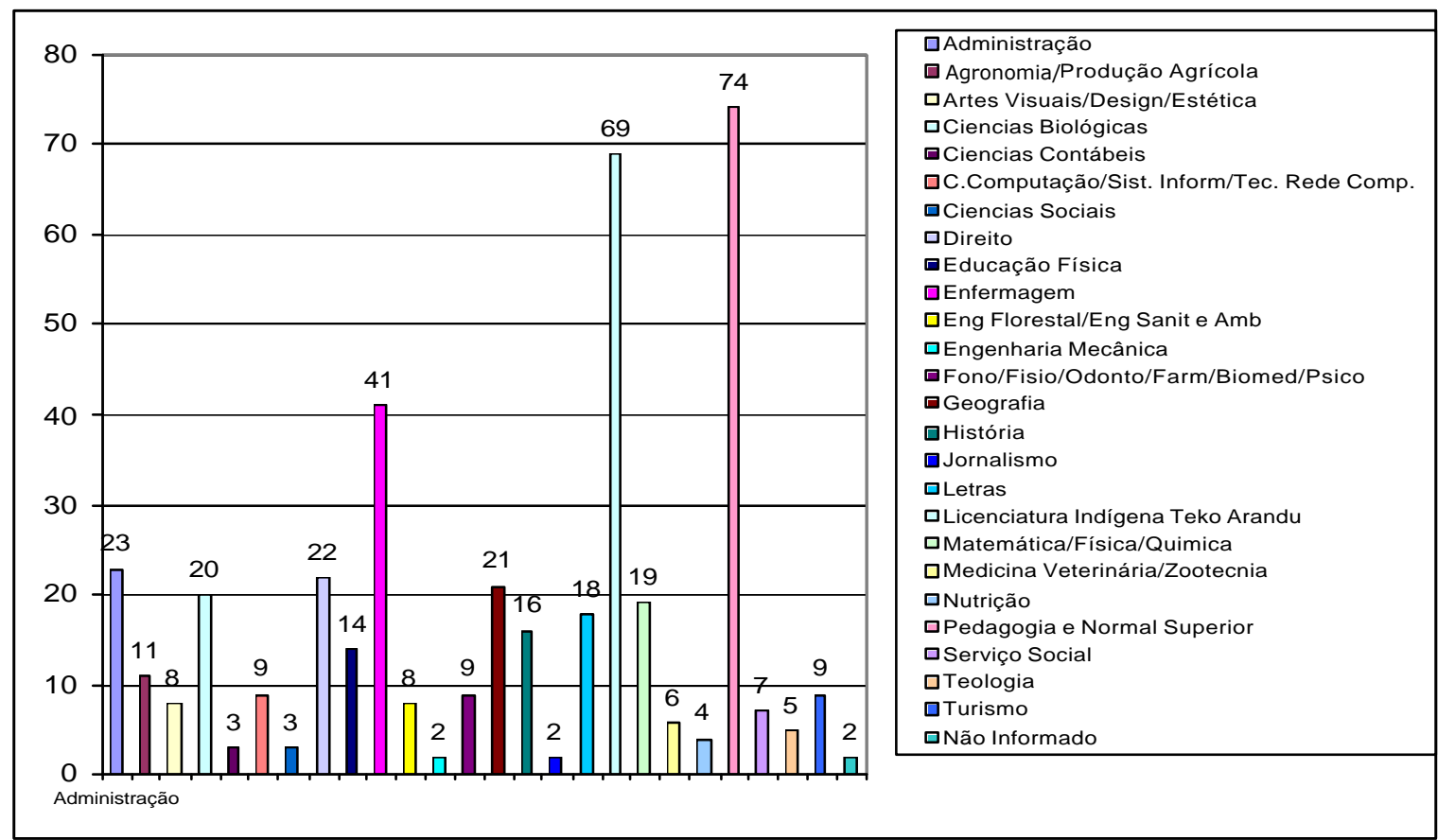

Figura 3 - Matrícula dos alunos indígenas nos cursos de graduação em 2009.

O gráfico acima confirma a afirmação de Souza Lima e Hoffmann (2004), que aponta dois vieses de acesso dos povos indígenas no ensino superior. Primeiro, a formação dos professores indígenas através das licenciaturas, destacando acima o curso de Pedagogia e Normal Superior, Biologia, Letras, Geografia, História e, posteriormente, os cursos da área da saúde como Enfermagem, Nutrição, Fisioterapia, Psicologia e outras áreas profissionais como Direito, Administração, Agronomia, que os capacitará a gestarem seus projetos de autonomia e sustentabilidade, sendo esta a expectativa dos jovens indígenas que a cada semestre adentram a universidade.

O significativo trabalho realizado pelo Programa Rede de Saberes com os acadêmicos indígenas, através de ações positivadas pela experiência de dois anos, obteve o reconhecimento das comunidades indígenas e acadêmicas, bem como da Fundação Ford, agência financiadora, possibilitando a aprovação de uma nova versão do projeto para o biênio 2008-2010.
$\mathrm{Na}$ atual versão, três mudanças são relevantes formando um novo arcabouço organizacional para o projeto. A inserção da UFGD - Universidade Federal da Grande Dourados e a UFMS - Universidade Federal de Mato Grosso do Sul - campus de Aquidauana, ampliando a rede de atendimento aos acadêmicos indígenas no Estado. A segunda diz respeito ao fortalecimento da articulação entre os estudantes das diversas IES e desses com suas comunidades e, por último, a implementação de um fórum de articulação com a participação de órgãos públicos, ONGs e outros, ampliando as discussões e busca de alternativas para quando os acadêmicos índios concluam seus estudos, tendo em vista o seu ingresso profissional no contexto regional.

\section{Educação Superior Indígena: os desafios de uma relação intercultural}

Atualmente, a educação vem se constituindo demanda importante na luta pelos direitos dos povos indígenas no Brasil. A 
partir das práticas concretas de educação indígena nas últimas décadas, já é possível perceber a influência da visão culturalmente diferenciada destes povos, a força que suas práticas rituais e míticas exercem, influenciando, de certo modo, até mesmo as propostas curriculares.

Segundo Silva (1998), a escolarização e o ensino podem ser considerados como políticos de diversas formas. Em primeiro lugar, e talvez de forma mais comum, está o reconhecimento de que as políticas de currículo, as condições de ensino e as práticas pedagógicas são orientadas pela política convencional dos governos estadual / municipal / local. Em segundo lugar, está o reconhecimento de que a escolarização está implicada na distribuição diferencial de conhecimento e recompensas simbólicas entre diferentes grupos de pessoas de tal forma que padrões de desigualdade social são mantidos através da participação ou não participação dos membros desses diferentes grupos.

Tradicionalmente, as IES têm organizado seu currículo em torno de disciplinas convencionais. Nesse tipo de divisão intelectual do trabalho, os estudantes geralmente têm poucas oportunidades para estudar questões sociais mais amplas através de uma perspectiva multidisciplinar. Entramos num período no qual as distinções que separam e enquadram as disciplinas acadêmicas estabelecidas não podem dar conta da grande diversidade de fenômenos culturais e sociais que caracterizam um mundo globalizado cada vez mais hibridizado (SILVA, 1998).

A universidade ainda tem-se pautado por uma noção de identidade nacional amplamente definida pela transmissão da cultura tradicional, ocidental, construída numa visão etnocêntrica, na qual uma cultura é superior e as outras culturas julgadas e explicadas como inferiores. A diferença não está só na cultura, mas sim nas posições sociais ocupadas pelas pessoas, nas diferenças de poder, na qual um subordina o outro; uma relação de dominados e dominantes. Uma visão de mundo universal, de linguagem única, superior e melhor. De imposições e verdades absolutas, na qual o desejo do colonizador foi de concretizar a unificação dos povos e da cultura.

Concretamente, essa tem sido uma cultura de exclusão, uma cultura que tem ignorado as múltiplas narrativas, histórias e vozes de grupos culturais e politicamente subordinados e a busca de novas alternativas ou a tentativa de produzir novas metodologias e novos modelos teóricos para analisar a produção, a estrutura e a troca de conhecimento. Esta perspectiva é valiosa porque aborda a questão pedagógica da organização do diálogo entre disciplinas e fora delas, a fim de promover abordagens alternativas de ensino e pesquisa sobre cultura, as tecnologias e formas de conhecimento.

No cotidiano das universidades constata-se uma clara resistência ao diferente por parte da comunidade acadêmica. Para muitos professores, apesar do número e da proximidade física dos povos indígenas, esta segue sendo uma realidade distante, desconhecida, perpassada por informações equivocadas e preconceituosas, com pouca ou nenhuma relevância para seu trabalho como docente (URQUIZA, 2007). Predomina na região e nas próprias Universidades, um forte sentimento "anti-indígena", assumido, abertamente, pelos grandes latifundiários, ligados ao agronegócio e veiculado, cotidianamente, pelos meios de comunicação. Mudar esse contexto, ideológica e historicamente construído, é um desafio a ser problematizado no contexto da educação superior.

$\mathrm{Na}$ verdade, este processo cria um novo contexto na moldura tradicional e erudita da universidade: a convivência entre as diversas formas de produção de conhecimento, que sempre foram vistas de forma separadas, hierarquizadas e acabadas. Essa presença acaba provocando o estudo dos processos de hibridação cultural, nos quais os saberes são respeitados em suas lógicas e naturezas e ressignificados a partir de outra leitura de mundo, uma leitura processada no respeito às diferenças. Com isso as instituições de ensino superior têm como grande desafio pela frente integrar as diferenças sem que, no entanto, essas diferenças sejam anuladas (NASCIMENTO, 2006).

\section{Considerações finais}

Os estudantes indígenas de Mato Grosso do Sul chegam ao ensino superior por várias portas: acesso universal, cotas, projetos específicos. Quantitativamente ainda 
representam um percentual baixo, mas que tem provocado grandes desafios, muitos questionamentos e inquietações de caráter epistemológico, metodológico, político e ético. De invisíveis anteriormente a visíveis hoje, buscam as IES para vencer o processo ininterrupto de pauperização que vem sofrendo ao longo dos tempos, buscando alternativas de autonomia e sustentabilidade. Neste processo, a educação vem se tornando um elemento chave na luta por melhores condições de vida para que as relações entre as pessoas culturalmente diferentes sejam de respeito e solidariedade.

Neste sentido, a educação superior indígena é, certamente, um projeto social e político que se insere numa perspectiva de construção e sedimentação da busca dos povos indígenas por reconhecimento de sua especificidade cultural. No entanto, isso só será possível se houver o devido respeito ao princípio da alteridade, previsto na legislação, e uma busca constante por uma educação específica, de qualidade e intercultural, não só para as atuais, mas para as futuras gerações de crianças, jovens e adultos indígenas.

O porvir dos povos indígenas no ensino superior reflete claramente as contingências da experiência histórica vivida. Buscam, de um lado, através de uma maior sistematização, fortalecer os seus conhecimentos tradicionais, sua história e língua e de outro, o necessário domínio dos assim denominados conhecimentos universais, considerados necessários para uma melhor inserção no entorno regional e relevante para os seus projetos de autonomia.

O risco, segundo Urquiza (2007), é que as instituições, em seus projetos de ensino superior para os povos indígenas, sigam passando ao largo dos processos mais amplos de busca de autonomia destes povos e centrem sua preocupação apenas em permitir o acesso dos índios aos seus ambientes acadêmicos, o que é, certamente, muito pouco.

Não se trata de questionar o direito dos povos indígenas ao ensino superior, mas das instituições se perguntarem sobre o tipo de ensino que oferecem aos povos indígenas. $\mathrm{O}$ desafio está posto, no sentido de repensar e construir novas concepções de ensino que, superando a fragmentação e questionando o saber academicamente sedimentado e hegemônico, que perpassa e está subjacente em nossas práticas pedagógicas, possa permitir o "exercício constante da interculturalidade" em todas as abordagens da realidade (BRAND, 2005).

Neste sentido, um projeto curricular emancipador, destinado aos membros de uma sociedade democrática e progressista, além de especificar os princípios de procedimento que permitem compreender e sugerir processos de ensino e aprendizagem, também deve propor metas educativas e blocos de conteúdos culturais que melhor contribuam para uma socialização crítica dos indivíduos. Afinal, segundo Urquiza (2006), a universidade, um conceito derivado do latim "universitas" e historicamente implantado na Idade Média européia tinha como identidade ser um espaço aberto para os saberes universais. Nada mais natural, na atualidade, que buscar restabelecer este sentido original do papel destas instituições: lócus de saberes diversos, representativos da diversidade sociocultural dos vários segmentos.

As instituições de ensino superior, ao abrirem espaço para o desafio de contribuir com a busca de novos caminhos de sustentabilidade desses povos, deverão estar abertas, também, para essa dimensão da diversidade de perspectivas de futuro, visualizadas pelas populações indígenas (URQUIZA, 2006). Infelizmente, este ainda não é o cenário vivido, as relações ainda são assimétricas, mas mudanças parciais já estão sendo percebidas, indivíduos indígenas antes invisíveis, hoje se posicionam abertamente com suas marcas de cultura e o transitar de um lugar para o outro, da aldeia a academia, não favoreceu o abandono do seu jeito de ser e de aprender.

\footnotetext{
Notas

${ }^{1}$ Lei n. 9.394/96 - Lei de Diretrizes e Bases da Educação Nacional - LDBEN; Plano Nacional de Educação PNE, aprovado em 2001 e o Referencial Curricular Nacional para as Escolas Indígenas - RCNEI, 1998.

${ }^{2} \mathrm{O}$ projeto Trilhas de Conhecimentos teve o seu início em fevereiro de 2004, financiado por uma doação da Fundação Ford, através da Pathways to Higher Education Initiative. O objetivo inicial era fomentar iniciativas de ação afirmativa desenvolvidas por universidades destinadas a dar suporte ao etnodesenvolvimento dos povos indígenas no Brasil, através da formação de indígenas no ensino superior. É gerenciado pelo LACED (Laboratório de Pesquisas em Etnicidade Cultura e Desenvolvimento) no Museu Nacional/UFRJ.
} 


\section{Referências}

BRAND, A. Autonomia e globalização, temas fundamentais no debate sobre educação escolar indígena no contexto do MERCOSUL. Série-Estudos - Periódico do Mestrado em Educação da UCDB, n. 7, abr. 1999.

Indígenas no ensino superior ou ensino superior indígena: experiências e perspectivas. In: CONGRESSO DE LEITURA DO BRASIL - COLE, 15. Campinas. Anais... Campinas: [s.n.], 2005.

Formação de professores indígenas em nível superior. QUAESTIO - Revista de Estudos de Educação, Sorocaba-SP, v. 8, n. 1, p. 73-82, maio 2006.

BRAND, A. J.; NASCIMENTO, A. C. A escola indígena e sustentabilidade - perspectivas e desafios. In: SEMINÁRIO INTERNACIONAL: EDUCAÇÃO INTERCULTURAL MOVIMENTOS SOCIAIS E SUSTENTABILIDADE - PERSPECTIVAS EPISTEMOLÓGICAS E PROPOSTAS METODOLÓGICAS, 3. Anais... Florianópolis: [s.n.], 2006.

BROSTOLIN, M. El papel da educación en programas de desarrollo local en populacions indígenas. 2005. Tese (Doutorado) - Universidade Complutense de Madri, Espanha, 2005.

BROSTOLIN, M. R.; CRUZ, S. F. Estilos de ensinagem e aprendizagem na escola indígena Terena. Revista Construção Psicopedagógica, v. 17, n. 14, p. 24-43, jun. 2009.

CRUZ, S. F. A criança Terena: o diálogo entre a Educação indígena e a Educação escolar na aldeia Buriti. 2009. 191p. Dissertação (Mestrado em Educação) Universidade Católica Dom Bosco, Campo GrandeMS, 2009.

LIMA, A. C. S.; HOFFMANN, M. B. Seminário:Desafios para uma educação superior para os povos indígenas no Brasil: políticas públicas de ação afirmativa e direitos culturais diferenciados. Relatórios de Mesas e Grupos. Brasília, out. 2004.

MANGOLIM, O. Da escola que o branco faz à escola que o indio necessita e quer: uma educação indígena de qualidade. 1999. Dissertação (Mestrado em Educação) - Universidade Católica Dom Bosco, Campo GrandeMS, 1999.

NASCIMENTO, A. C. Populações indígenas, universidade $e$ diferença. In: ANPED - CENTRO OESTE. Anais... Cuiabá, 2006.

SANTOS, M. (Org.) Território: globalização e fragmentação. São Paulo: Hucitec/Ampur, 1994.

SILVA, T. T. (Org.). Alienígenas na sala de aula: uma introdução aos estudos culturais em educação. 2. ed. Petrópolis: Vozes, 1998.

TAUKANE, D. A história da educação escolar entre os KurâBakairi. Cuiabá: Gráfica Print, 1998.

URQUIZA, A. H. A. Educação indígena e sustentabilidade: questões para a antropologia. In: ABA. Anais ... Goiânia, 2006.

Relatório do Programa Rede de Saberes. Campo Grande: UCDB, 2007. 